\title{
HOWARD BECKER: ¿EL CONTEMPORÁNEO DE LA ESCUELA DE CHICAGO? LA TEORÍA DEL ETIQUETAMIENTO EN EL PROCESO DE CRIMINALIZACIÓN
}

\author{
HOWARD BECKER: THE CONTEMPORARY OF THE CHICAGO SCHOOL? \\ THE THEORY OF LABELING IN THE PROCESS OF CRIMINALIZATION
}

\author{
Wael Hikal \\ Sociedad Mexicana de Criminología Capítulo Nuevo León \\ wshc1983.2013@gmail.com \\ México
}

\section{SUMARIO}

- Breve reseña biográfica

- Antecedentes de la teoría del etiquetamiento

- Discusión

- Proceso de desviación

- Cuándo se etiqueta una conducta

- Criterios de desviación

- El cuándo y dónde de la conducta desviada o criminal

- El poder de etiquetar: los empresarios morales

- Clasificación de los delincuentes según Becker

- Control social y desviación

- Conclusiones

- Referencias bibliográficas

\section{RESUMEN}

Becker es un autor que sobrevive a los clásicos y precursores de la Escuela de Chicago, nicho de grandes creadores de teorías influyentes en el contexto de la sociología y la criminología por las explicaciones de interacción, aprendizaje, exclusión, estructuras sociales, entre otras. Él elabora una síntesis que pareciera ser perfeccionada y potencialmente más aceptada y adaptada al momento actual con los resultados que suelen dar las buenas síntesis a través de los medios más adecuados de difusión $y$, sobre todo, la argumentación de los experimentos y revisiones teóricas. Así, en el presente, se muestra la teoría del etiquetamiento y los procesos de calificación de conductas desviadas, quiénes las estigmatizan como tales y los efectos sociales que provocan.

\section{PALABRAS CLAVE}

Empresarios morales, etiquetados, interaccionismo simbólico, sociología de la desviación, teoría del etiquetamiento.

\begin{abstract}
Becker, author who survives to the classics and predecessors of the Chicago's school, niche of great creators of influential theories in the context of sociology and criminology, by explanations for interaction, learning, exclusion, social structures, among others. This author, comes to realize a synthesis, that seems to be perfected and potentially more accepted and adapted to the present time, with results that often gives the good synthesis, along with the appropriate media, and above all, the argumentation of the experiments and theoretical reviews. Thus, in the present, shows the theory of labeling, along with the processes of qualification of deviant behaviors, who stigmatize them as such and the social effects that cause.
\end{abstract}

\section{KEYWORDS}

Moral entrepreneurs, labeled, labeling theory, sociology of the deviation, symbolic interactionism. 


\section{BREVE RESEÑA BIOGRÁFICA}

Becker nació el 18 de abril de 1928 en Chicago, Illinois. Estudió Sociología en la Universidad de Chicago y tuvo como guías a Robert Park, Herbert Blumer y Everett Hughes. Además, ha sido desarrollador del jazz. Escribir sobre los grupos de este género musical lo llevó a interesarse por el estudio del consumo de drogas y la desviación, por lo que escribió sobre ello.

Se doctoró en 1951 y fue profesor de Sociología en la Universidad Northwestern en 1965, donde enseñó hasta 1991. Fue editor de la revista Problemas sociales de 1961 a 1965. Desde 1999 enseña en la Universidad de California, en Santa Bárbara. Asimismo, es miembro de la Academia de Artes y Ciencias desde 1993.

De su página web se extraen los títulos de sus obras publicadas; sus observaciones están dirigidas hacia diversas áreas del conocimiento como arte, música, sociología, criminología, entre otras (Howies Home, 2016): Thinking together: An e-mail exchange and all that jazz; What about mozart? What about murder?; Trucos del oficio. Cómo conducir su investigación en ciencias sociales (1998); Los extraños. Sociología de la desviación (1963); Los mundos del arte (1982); Telling about society (2007); Escribiendo para cientificos sociales (1986); El arte desde el inicio al fin, Paroles et musique, Propos sur l'art, Chicos en blanco. Estudios culturales en la escuela de Medicina (1961); Logrando el grado. El lado académico de la vida colegial (1968); Trabajo sociológico: Método y sustancia (1970). Algunas de estas obras están publicadas en la editorial Siglo XXI (Siglo Veintiuno Editores, 2016).

En síntesis:

Sociólogo nacido en Chicago en 1928. Trabajó como pianista profesional y orientó sus primeras investigaciones a explorar el mundo de los músicos de jazz y del consumo de drogas, con el propósito de intervenir críticamente en el campo de la denominada «sociología de la desviación». En esta línea, sentó las bases de la teoría del etiquetamiento. Inicialmente, su obra analiza las interacciones simbólicas a la luz de las diferencias de raza, estatus y poder, pero abarca también otras áreas de indagación, como la sociología del arte, la práctica de la investigación cualitativa y la escritura en las ciencias sociales (Siglo Veintiuno Editores, 2016).

\section{ANTECEDENTES DE LA TEORÍA DEL ETIQUETAMIENTO}

Winslow y Zhang (2008) aportan datos sobre el desarrollo de esta teoría:

Labeling theory was developed by Howard S. Becker in his 1963 book Outsiders: Studies in the Sociology of Deviance. Becker's theory was rooted in the tradition of the Chicago School of Criminology in the symbolic interaction foundation of Cooley and Mead, as well as the labeling influences of Frank Tannenbaum and Edwin Lemert (p. 115).

Señala Reyes Calderón (2007) que Tannenbaum es el primero en formular: "The young delinquent become bad, because he is definided as bad». De este modo, puede ser considerado el "primer padre» del Labeling Approach, que considera las reacciones y definiciones del medio, con respecto a un determinado comportamiento, como decisivas para la aparición del comportamiento desviado (p. 227).

El trabajo de Tannenbaum fue mostrado en su libro Crimen y la comunidad, publicado en 1938, en donde popularizó el término "etiquetar» para explicar lo que ocurre a los ofensores cuando son arrestados y sentenciados.

Schmalleger (2006) abunda:

As the problem develops, the situation gradually becomes redefined. The attitude of the community hardens definitely into a demand for supression. There is a gradual shift from the definition of the specific acts as evil to a definition of the individual as evil, so that all his acts come to be looked upon with suspicion... From the community's point of view, the individual who used to do bad and mischievous things has now become a bad and unredeemable human being... The young delinquent becomes bad because he is defined as bad and because he is nor believed in character. The community can not deal with people whom it cannot define (p. 254).

Tannenbaum se refiere a un proceso de dramatización del mal, en el cual el ofensor 
pasa a convertirse en lo más malo de la sociedad y lo último de la que esta desea saber. Así, el ofensor vive en un mundo diferente. Ha sido etiquetado, y el proceso de criminalización antecede a una etiqueta. De ese modo, el criminal $u$ ofensor se limita a interactuar solo con otras personas que estén en su misma situación. Así, estas identificaciones con otros negativos conducen a reiterar las actividades desviadas (Reyes Calderón, 2007, p. 227).

Por otro lado, cronológicamente, fue Lemert quien sería considerado el refundador del Labeling approach, pues se valió de tales conceptos para desarrollarlos nuevamente. No obstante, se considera principalmente a Becker el mayor asociado a esta corriente, dado que aportó más a esta teoría y fueron más conocidas que las realizadas por Lemert. Así, los escritos de Becker son los que generaron mayor impacto (Reyes Calderón, 2007, p. 227).

\section{DISCUSIÓN}

Winslow y Zhang (2008) explican la diferencia entre la teoría de Sutherland y la de Becker:

Becker's statement of labeling theory is (like Sutherland's exposition of differential association theory) a more radical approach to symbolic interactionism than that of any of his predecessors. In Outsiders: Studies in the Sociology of Deviance, he argued that deviance is the creation of social groups rather than the quality of some act or behavior. He argued against studying criminal behavior itself, because such behavior is simply deviance that has been labeled as such by people in positions of power who may benefit by the labeling and enforcement of rules against such behavior (p. 116).

1. Señala que, ante el hecho delictuoso, las instituciones reaccionan de dos modos: institucional y no institucionalmente.

2. Tal reacción surge posterior al delito.

3. Interacción entre el delito y reacción social.

Las instituciones a las que se refiere pueden ser de dos tipos:
1.Formales: las legitimadas por las autoridades como medios normados, ejecutivos, el Derecho Penal, la política criminal, la policía, las instituciones de gobierno, administradoras de justicia, persecutorias, etcétera.

2. Informales: la familia, escuelas u otras instituciones de educación, medios de comunicación (en el entendido que den un mensaje positivo y neutralizador), el empleo u otras ocupaciones laborales, iglesias o medios religiosos.

Pérez Pinzón y Pérez Castro (2006) sostienen:

[...] H. Becker explica que todo grupo social hace reglas para prescribir actuaciones como correctas e incorrectas, de donde se desprende que el hecho fundamental de la desviación estriba en que esta es creación de la sociedad, no en el sentido de que sus causas se encuentran en la situación social o en los factores sociales, sino en el hecho de que los grupos sociales generan la desviación al confeccionar las reglas cuya infracción la constituye y al aplicar dichas normas a determinadas personas. Desde este punto de vista, la desviación no es una cualidad del acto cometido por la persona sino una consecuencia de la aplicación que los otros hacen de las reglas y de las sanciones para un ofensor. En fin, agrega Becker, aparte de lo anterior, que un acto sea desviado depende de quién vulnera las reglas, contra quién y cómo reaccionan los demás (p. 95).

\section{PROCESO DE DESVIACIÓN}

Se señala que lleva consigo un proceso o una serie de pasos; a saber: la sociedad genera expectativas de comportamiento; este (no desviado aún) se da en él; dicha conducta se rotula como «desviada».

Entonces, el individuo ya realizó una conducta desviada. Tal estigma genera reacciones sociales en contra (en otros casos de aceptación, como se vio en la subcultura criminal). Finalmente, aunque no completa la explicación de este proceso, la interacción entre la conducta y la reacción social genera otro tipo de comportamientos, ya sea de temor, persecución, vanidad, 
rechazo, aceptación, exclusión, violencia, agresividad, entre otros.

Por su parte Winslow y Zhang (2008) explican:

Once a person has accepted the deviant label as his master status, he becomes an outsider and is denied the means of carrying on everyday life. Once it happens, the outsider turns to illegitimate means to make a living. Finally, the person becomes involved in a deviant subculture that provides moral support and a selfjustifying rationale, and through such association the person may learn new forms of deviance through differential association (p. 116).

Por otro lado, dentro de este proceso, se encuentra, como ya se señaló, crear una conducta que queda etiquetada $\mathrm{y}$, posteriormente, se empodera y refuerza al crear una institución encargada de etiquetar, perseguir, sancionar, castigar, y humillar tal conducta. En paralelo, se tiene la invasión mediática, en la que los medios se han convertido en agencias investigadoras y enjuiciadoras, además de encargados de hacer públicas a las personas, domicilios, nombres, situaciones, etcétera.

Sobre el proceso de creación de las reglas, Hopkins Burke (2009) indica:

Becker argued that rules -including criminal laws - are made by people with power and enforced upon people without power. Thus, even on an everyday level, rules are made by the old for the young, by men for women, by whites for blacks, by the middle class for the working class and we might add here, by schools for their students and parents for their children (...). As a result of this process, most people internalise and obey the rules without realising - or questioning- the extent to which their behavior is being decided for them (p. 168).

En otro contexto, se puede percibir que las reglas son hechas por algunos para mantener el poder, que, de hecho, suele ser de ese modo. Al hacer reglas, en efecto, se regula, norma, controla, y limita la conducta. Y es una forma de tener superioridad, dicha que ha sido proliferada a través de otras formas, por ejemplo laborales, con la burocracia, familiares con las jerarquías, escolares, etcétera.
Sobre lo anterior y los grupos de poder, se puede observar en la legislación la creación de delitos, que en muchas ocasiones luce focalizada a determinados grupos minoritarios, contrario a los delitos dirigidos a los de alto nivel. Por ejemplo, preguntémonos: en el país donde vivimos, ¿cuándo vemos con recurrencia casos de servidores públicos encarcelados por abuso de autoridad, desvío de recursos, corrupción, defraudación fiscal?

Lo anterior queda borrado de la frecuencia estadística, dado que esos mismos grupos de poder se blindan, y se convierten en los principales ejecutores de las conductas antes señaladas.

El término outsider se emplea para comprender a alguien que vive apartado de las normas sociales; es alguien que está afuera del grupo. El desviado es un producto de la sociedad y a su vez es alguien no aceptado por no saber, querer o poder vivir bajo las normas sociales de los grupos que las crean.

Schmalleger (2006) explica en palabras de Becker:

Social groups create deviance by making the rules whose infraction constitutes deviance, and by applying those rules to particular people and labeling them as outsiders. From this point of view, deviance is not a quality of the act the person commits, but rather a consequence of the application by others of rules and sanctions... The deviant is one to whom that label has been successfully applied (p. 255).

Por su parte, Lamnek apunta que, según Becker: «Desde el punto de vista del individuo que es etiquetado como desviado, pueden ser outsiders aquellas personas que elaboran las reglas, de cuya violación fue encontrado culpable». (Lamnek, 2006, p. 57)

\section{CUÁNDO SE ETIQUETA UNA CONDUCTA}

Labor compleja resulta «etiquetar» una conducta por todo lo que implica ese enjuiciamiento. A saber, aquí se toma en cuenta el tiempo y espacio en el que se presenta dicha conducta. 
Winslow y Zhang (2008) explican:

Tagging involved defining, identifying, segregating, and singling out individuals for special treatment. A consequence of tagging is the stimulation, suggestion, and evoking of the very traits that the person is accused of. The person becomes the thing they are accused of being (p. 115).

Pérez Pinzón y Pérez Castro (2006) agregan:

Una ojeada al desarrollo del labelling permite concluir que es probable que este se inicie con las investigaciones de Tannenbaum, quien en 1938 ya mostraba cómo el delincuente era malo porque aparecía definido como tal, es decir, que las reacciones y definiciones del medio respecto de un determinado comportamiento eran decisivas para que surgiera la conducta desviada.

Con estas palabras breves puede ser resumida la teoría: la criminalidad no es una cualidad de determinada conducta, sino el resultado de un proceso de atribución de tal cualidad, de un proceso de estigmatización. La criminalidad es una etiqueta que se aplica por el legislador, la policía, los fiscales y los jueces. Por ello, la aposición del rótulo procede de las instancias formales o informales de control social (p. 94).

A continuación se muestra un cuadro sobre algunas conductas que varían según el tiempo y el contexto geográfico donde se esté:

\begin{tabular}{|c|c|c|}
\hline \multicolumn{3}{|c|}{ NORMALIDAD, ANORMALIDAD Y DESVIACIÓN } \\
\hline Condición & Análisis & Variable (desviación) \\
\hline \multicolumn{3}{|c|}{ En cualquier caso, la perspectiva-aceptación no es unificada } \\
\hline Aborto & $\begin{array}{l}\text { Hay regiones geográficas donde se } \\
\text { ha despenalizado: pasó a ser una } \\
\text { conducta aceptable. }\end{array}$ & $\begin{array}{l}\text { Hay regiones geográficas donde es } \\
\text { delito: es una conducta apartada de } \\
\text { la norma y se castiga. }\end{array}$ \\
\hline Homosexualidad & $\begin{array}{l}\text { En algunas geografías dejó de ser } \\
\text { trastorno y/o delito. Se legalizó el } \\
\text { matrimonio. }\end{array}$ & $\begin{array}{l}\text { Hay geografías donde es delito o } \\
\text { prohibición. }\end{array}$ \\
\hline Consumo de sustancias & $\begin{array}{l}\text { En algunos lugares es aceptable } \\
\text { el consumo de nicotina, alcohol, } \\
\text { cafeína, marihuana, etcétera. }\end{array}$ & Otros lugares donde es sancionado. \\
\hline $\begin{array}{l}\text { Uso de pelucas, faldas, } \\
\text { maquillaje en los hombres }\end{array}$ & $\begin{array}{l}\text { En la Antigüedad era un estilo de } \\
\text { moda, necesario. }\end{array}$ & $\begin{array}{l}\text { Actualmente, es etiquetado como } \\
\text { travesti, transexual, homosexual } \\
\text { afeminado y completamente } \\
\text { inaceptable en lugares públicos. }\end{array}$ \\
\hline Iniciación sexual & $\begin{array}{l}\text { En algunas partes, el padre inicia a las } \\
\text { hijas y/o arregla la unión conyugal. }\end{array}$ & $\begin{array}{l}\text { En otros lugares, es mal visto, } \\
\text { inaceptable, punible. }\end{array}$ \\
\hline Religión & $\begin{array}{l}\text { Existe la creencia de dioses: el Sol, } \\
\text { agua, lluvia, Luna, constelaciones, } \\
\text { buda, virgen, Jehová, Jesús, Alá, } \\
\text { entre otros. }\end{array}$ & $\begin{array}{l}\text { En cada región/tiempo, se tiene } \\
\text { preferencia hacia algo determinado. }\end{array}$ \\
\hline
\end{tabular}


En lo anterior, influye lo siguiente:

- El contexto histórico: lo normal, anormal o desviado varía según el tiempo, como se vio en el cuadro anterior. Por ejemplo, los dioses han ido cambiando, se han creado nuevos y eliminado otros, arraigando a algunos; según la época, será la existencia de las divinidades. Anteriormente, en nuestro contexto, se adoraba a ciertos animales, se les daba el grado de dioses, o a las constelaciones, estrellas, etcétera. Posteriormente se impone un nuevo dios, Jesús de Nazaret, cuyo arraigo ha sido en general de 2016 años, y fue tal su poder, que partió los tiempos del planeta Tierra en antes de Cristo (a.C.) y después de Cristo (d.C.).

- El espacio geográfico: otro ejemplo es el de la homosexualidad. En México, se impone progresivamente que la unión entre personas del mismo sexo sea legalizada, así como su cambio de nombre legal para las personas trans. Este movimiento no había ocurrido de modo imponente hasta hace poco, no más de tres años a la publicación de este libro. En otras regiones e igualmente otros tiempos, han sido determinantes en la percepción sobre este fenómeno: Hay aún lugares donde es sancionado penalmente; otros, donde no es bien visto que las parejas homosexuales tengan muestras de afecto en público como el resto.

- Situaciones o lugares en específico: el consumo de bebidas alcohólicas es aceptado cultural y legalmente, aunque con determinadas restricciones. Se ha prohibido que se lleve a cabo en la vía pública por los efectos que estas sustancias producen y que en ocasiones peligran la vida propia o de otros; sin embargo, a pesar del riesgo, se permite. Por ello, se limita a lugares destinados a dicha actividad (bares, casas u otros). Lo mismo la religión: no es bien visto que una persona esté orando en el transporte público o en la calle, a menos sea una situación de emergencia y se justifica. Otra situación sería cuando ocurre un accidente de tránsito; si hay heridos, quienes asisten en auxilio están facultados para romper ropas e incluso quebrar partes de los vehículos porque la situación lo requiere.

Luego de lo visto, resulta de relevancia tomar en cuenta estos elementos de manera objetiva, alejada de los prejuicios personales, la educación familiar o de nuestra propia cultura. Si estamos en un contexto donde el hombre golpea a sus hijos severamente como medio correctivo y la cultura de ese contexto es así, habrá que considerarlo. No corresponde al criminólogo-criminalista emitir un juicio moral, sino investigar, interpretar y describir lo observado para recomendar acciones si resulta una afectación, siempre basado en derechos humanos y con respeto a las costumbres.

Reyes Calderón (2007) sostiene que:

El acto de inyectar heroína en una vena no es desviado en sí mismo. Si una enfermera administra drogas a un paciente cumpliendo órdenes de un médico, todo está perfectamente en orden. El acto se convierte en desviado cuando se hace en una forma que, públicamente, se considera indebida (p. 229).

Infinidad de ejemplos como el anterior se pueden tomar a análisis; a saber algunos:

- Vemos a un hombre ensangrentado y con un cuchillo en la mano. ¿Qué pensamos? ¿Es un asesino? ¿Es un carnicero?

- Un sujeto corta el antebrazo a otro sujeto. ¿Es tortura criminal? ¿Es un médico en el ejercicio de su profesión para salvar el resto del cuerpo?

- Una persona administra una droga para inducir al sueño a otro. ¿Es un criminal? ¿Es un psiquiatra?

- Un individuo observa los órganos sexuales de un menor de edad. ¿Es un pervertido? ¿Es un pediatra?

- Personas matan a otras con armas. ¿Son criminales? ¿Son policías en combate ante criminales?

- Personas invaden otro país para matar a otros. ¿Son terroristas? ¿Son militares en guerra?

- Un hombre golpea a una mujer desconocida. ¿Es un violentador? O, suponiendo, ¿esta mujer estaba secuestrando a su hijo?

- Alguien observa situaciones no autorizadas por los observados. ¿Es un espía o un mirón? ¿Es una misión de reconocimiento? 
- En determinado lugar nos solicitan la contraseña de nuestra tarjeta de crédito o débito. ¿Es para efectuar un mal uso de nuestros datos? ¿Es alguien autorizado para apoyarnos con algún trámite?

Etcétera.

\section{CRITERIOS DE DESVIACIÓN}

Respecto del primer ejemplo, continúa con su explicación Reyes Calderón (2007, p. 227) sobre los criterios de desviación, tomando de referencia los parámetros siguientes:

\section{Criterio institucional}

La conducta desviada, criminal o antisocial es considerada como tal porque se aparta acusadamente de las expectativas culturales. Como se vio en el cuadro anterior, la misma sociedad clasifica y desclasifica las conductas normales, anormales, desviadas, sociales, privadas, etcétera.

\section{Criterio estadistico}

Las mismas señaladas son las que se separan del número más frecuente de actos o hechos ocurridos. Por ejemplo, volviendo a considerar el tiempo y espacio, las muertes ocurridas en tiempos de guerra son aceptables y legales por quienes imponen tal acción; es decir, la matanza se legaliza cuando las «condiciones» así lo ameritan (¿?) según los gobernantes.

\section{Criterio moral o humanista}

Tales actos ofenden la moral. Si bien hay conductas que varían según el lugar donde se esté, hay otras que son criterio universal de ofensa a la humanidad; por ejemplo, el homicidio, ya sea legalizado o no.

Si por otro lado, se toma en cuenta la infidelidad o tener diversas parejas, son criterios que dependen del individuo, de la pareja, de la cultura, región, entre otros. Por ejemplo, en regiones donde son permitidos los matrimonios con varias mujeres, en la cultura machista se percibe en parte como un deseo que muchos quisieran.

Por otro lado, existen parejas que abiertamente aceptan la variedad de relaciones íntimas; a pesar de ello, tal hecho se percibe como lastimoso para otras culturas.

\section{Criterio por definición}

Finalmente ¿quién define la conducta y bajo qué criterios? En este caso y en esta época, los académicos, científicos, trabajadores de campo, legisladores, gobernantes, entre otros. Por lo tanto, en cada estado de la república mexicana existe una legislación para diversas materias de la vida: civil, familiar, penitenciario, penal, etcétera, las cuales varían a pesar de ser un país en conjunto; lo mismo sucede de país en país. De igual manera, varía la definición entre ciencias; por ejemplo, cómo es conceptualizada la desviación desde el punto de vista sociológico, psicológico, jurídico, criminológico, estadístico, entre otros.

Por lo tanto, cabe preguntarse: ¿desviado quién? ¿Quién dice si es así o no? ¿Criminal quién? ¿Delincuente quién? Puede haber muchos criminales regados, cuya conducta no ha sido investigada, descubierta o juzgada; por ello, no logran tal término de "delincuentes», sino hasta que los órganos encargados los tienen en sus manos y los clasifican.

Es importante recordar lo que sostenía Lacassagne: «Las sociedades tienen los delincuentes que se merecen» (Quirós, 1995, pp. 89 y 90). Y según Winslow y Zhang: «La criminología incluye el estudio de la justicia criminal, en el supuesto de que esta determina el crimen y, en otros casos, puede producirlo» (Winslow \& Zhang, 2008, p. 2).

\section{EL CUÁNDO Y DÓNDE DE LA CONDUCTA DESVIADA O CRIMINAL}

Entonces, puede que en nuestra sociedad se cometa gran cantidad de infracciones a las normas; sin embargo, ellas no constituyen conductas desviadas o criminales hasta que un grupo social las rotule como pertenecientes a esa condición. Tal sujeto pasa a adherirse a alguna de estas categorías cuando la reacción social actúa en su contra - que igualmente puede ser violenta y que por ello se hace énfasis en el respeto a los derechos humanos sin importar la condición o el hecho cometido por alguien-

Se etiqueta al individuo como tal; por ejemplo: en un nuevo código penal se crea la figura de delito «homosexual». Al momento de la publicación de esa reforma o adhesión al código, esto se traduce en miles o millones de criminales persiguiendo a todos aquellos que tienen esta tendencia. 
Otro ejemplo: cuando se crea como infracción fumar en lugares cerrados, ¿habrá la suficiente cantidad de policías, servicios periciales y jueces para investigar, perseguir y sancionar? Asimismo, si se tipificara o si se empoderara el respeto por la vida de los animales (en este caso, limitándonos solamente a los más callejeros o caseros como perros, gatos y pájaros), cuando se les atropelle, ¿habrá igualmente suficiente cantidad de policías, peritos, jueces y cárcel para tanto violentador de animales?

Citan Pérez Pinzón y Pérez Castro a Clarence Schrag:

1. A pesar de que ningún acto es intrínsecamente criminal, puede ser catalogado como tal por la ley.

2. Las definiciones de hechos criminales rigen en favor de los grupos poderosos mediante la acción de sus representantes, incluyendo a la policía.

3. Una persona no se convierte en criminal por violar la ley, sino principalmente porque las autoridades, a través del proceso de etiquetamiento, le confieren esa posición.

4. Clasificar a los hombres en criminales y no criminales choca contra el sentido común y la evidencia empírica, porque jamás se ha demostrado ni se percibe diferencia alguna entre unos y otros.

5. Mientras muchas personas pueden ser responsables de delitos, solamente unas pocas son aprehendidas por violación de la ley.

6. A pesar de que las sanciones legalmente previstas se dirigen a la totalidad del conglomerado, su severidad y consecuencias varían según las características del agresor.

7. La aplicación y la ejecución de las sanciones cambian de acuerdo a determinados rasgos distintivos como pertenecer a ciertos grupos minoritarios, ser transeúnte, de pobre educación, residente de determinadas zonas deterioradas, y otros factores personales y grupales.

8. Una vez que se recibe la etiqueta de criminal, es muy difícil para una persona desprenderse de ella y retornar a su correspondiente estatus social (Pérez Pinzón y Pérez Castro, 2006, p. 96).
La clasificación de estas conductas depende de la imposición que las autoridades ejecuten; es decir: solo se conoce como criminal, desviado o delincuente a aquel que ha sido identificado, investigado, perseguido y capturado. Por otra parte, las agencias informales, como lo son el resto de la sociedad, igualmente señalan, apuntan, etiquetan, estigmatizan y excluyen a determinadas personas.

De nuevo, Lamnek cita a Becker y Sack:

Becker considera como esencial aquí el aspecto del poder, que fue ya señalado por Sack [...] con especial énfasis: "Los grupos cuya posición social les proporcionan armas y poder están en mejores condiciones para imponer sus reglas. Diferencias de edad, de sexo, étnicas y de clase están todas referidas a diferencias en el poder, las que a su vez son responsables de las diferencias de grado en la capacidad de los diferentes grupos para formular reglas para otras personas» (Lamnek, 2006, p. 59).

\section{EL PODER DE ETIQUETAR: LOS EMPRESARIOS MORALES}

Becker considera y trabaja con el término empresarios morales, quienes son grupos de poder que gestionan que determinadas conductas lleguen a ser tipificadas como desviadas, criminales o delincuenciales, por lo que a su vez consiguen que obtengan una sanción y etiqueta. Durante este proceso, estos «empresarios morales», logran un reconocimiento y empoderamiento al ser representantes de la sociedad y abogar por el cuidado de esta, el resto; es decir, los desviados son la minoría sobre la cual recae el repudio de la sociedad.

Lo anterior es bien observado en los partidos políticos, en que sus dirigentes señalan culpables a los demás dirigentes, de tal modo que en cada periodo electoral o controversia surgen dirigentes en papel de observadores, investigadores, jueces y sancionadores, en que todos tienen la culpa, todos son corruptos, impunes, defraudadores, excepto los de su propio partido.

De las características de estos empresarios morales, se encuentran las siguientes: 
1. Desarrollan una actividad empresarial, ya que un solo individuo no califica conductas e influye en que los demás lo hagan notar como desviadas. Es una acción en conjunto; pero no confundir: los jueces ejercen en lo individual, teniendo como referencia lo que un colectivo previamente ya realizó. Lo contradictorio de ello, si puede ser notado así, es que los legisladores tal vez jamás fueron jueces y estos jamás han sido legisladores; por ello que se critique duramente a los poderes del país, en un vaivén de confusiones entre quienes legislan (el marco teórico de referencia) y quienes ejecutan (ejercen lo que indica el marco teórico).

2. Incluye un hecho público. Afortunadamente se ha transparentado el proceso de creación de leyes, se tiene canal televisivo abierto de las cámaras legisladoras, así como de otros órganos y poderes, como el judicial. Se puede tomar de referencia lo que señalaba Beccaria sobre las características de las conductas clasificadas como delitos, y que años más tarde se exhorta a hacer los documentos públicos, salvo que ese mismo grupo de poder etiquete determinada información como confidencial.

3. Tal actividad trae beneficios de poder $y$ prestigio; es un acto místico de consolidación con representación $y$ figuración de semidioses, deidades, autoridades, donde son guías del pueblo, y este debe someterse a sus mandatos, decisiones e imposiciones. A su vez, se despliega un manto protector donde estos evitan cierto tipo de sanciones también y tienen más beneficios. Por ejemplo, para los policías de cualquier orden gubernamental o las fuerzas armadas, el uso de la fuerza está permitido bajo el empleo de armas o técnicas de combate. Al mismo tiempo, tales ejecuciones son excusadas y perdonadas (hasta ciertos límites que las mismas autoridades establecen). Para el caso de los legisladores, si hay una controversia en la que se contradiga la nueva norma con alguna otra suprema, no se culpa al legislador, sino al Estado. Al inicio de su publicación, las leyes llevan el nombre del presidente que durante su "mandato» las ha expedido; sin embargo, tampoco a este se le juzga por una ley controvertida, sino al Estado, que, a fin de cuentas, golpea a la sociedad, pues en una retribución económica por algún daño causado, los recursos provienen de los ciudadanos.

Larrauri sintetiza los criterios de interacción que ocurren en el funcionamiento de la reacción penal entre el ente etiquetador-represor, la sociedad, delincuentes y víctimas:

- La interacción del policía con el infractor: dependiendo de la imagen que el policía se forme del infractor por su edad, raza, forma de vestir, forma de comportarse, el policía puede considerar que está fundamentalmente ante un «buen chico»y, por consiguiente, cesar toda actividad posterior o, por el contrario, puede entender que se halla ante uno «que merece escarmiento» e iniciar todo el proceso penal.

- La interacción del policía con la víctima: en atención a la posición social de la víctima, a la insistencia de esta, a la opinión que la policía se forme de ella, a la relación que esta tenga con el delincuente, la policía se inclinará a iniciar los trámites legales o, por el contrario, pretenderá convencerla acerca de la inutilidad de iniciar un proceso legal.

- La diferente organización de la policía puede, asimismo, conllevar diferencias en la atención que se dedique a diversos delitos. Una ciudad que posea una comisaría especialmente dedicada a atender los delitos contra las mujeres es probable que registre un mayor índice de estos delitos que otra ciudad que carezca de estos servicios y en donde el hecho de denunciar sea más dificultoso, o donde no se lleve un registro $\tan$ minucioso al respecto.

- Los cambios en las políticas policiales también pueden ocasionar una persecución diferenciada. Así, una circular del fiscal general que señale la necesidad de prestar más atención a la violencia doméstica o al abuso sexual de menores, puede concluir en que la policía dedique un mayor esfuerzo a estos problemas o sea más receptiva a las denuncias, lo que probablemente ocasionará un incremento en el índice de delitos registrado. 
- Finalmente, la propia concepción que la policía tenga de su trabajo influirá también en el tipo de delitos que se persiguen; así, la policía puede considerar que determinados problemas son asuntos de trabajo social o minucias, o que difícilmente originarían un proceso $\mathrm{y}$, por consiguiente, no sentirse predispuestos a darle la atención que estos requieren (Larrauri, 2009, p. 34).

1. En el primer caso, es muy cotidiano que la policía estigmatice a determinados grupos, a pesar que las teorías de Lombroso sobre etiquetar determinada apariencia física se considera superada. No ocurre así cuando en las calles vamos clasificando personas según su forma de vestir, hablar, actuar y físico; nos protegemos de determinadas personas que reúnen las características mediáticas que se nos ha enseñado. Por parte del policía, la situación es similar: persigue, detiene, identifica y captura al azar o por ciertas características en los grupos.

2. La víctima que tiene el valor de denunciar, tiene un papel insistente y de sufrimiento, así como de causar presión hasta lograr se le dé atención. Esta, a su vez, ofrece una primera descripción del presunto criminal y, como se señaló en el punto anterior, viene acompañada de un estigma, donde se ha de señalar a «sujetos peligrosos » (esta etiqueta se da con la vista). En algunos casos, el policía invita a la denuncia; en otros, se arreglan con el presunto criminal o ignoran la atención. Ocurre que cuando más se requiere a la policía, estos extrañamente no están. Hace tiempo surgió un meme bastante divulgado en las redes, en el que se criticaba la función policial a manera que ante el pueblo, en una manifestación, por ejemplo, están presentes y rudos, hasta parecer un muro de choque, contención, confrontación, pero ante los criminales organizados de alto nivel, son ausentes, desaparecidos, sumisos.

3. Es evidente que el gobierno hace y deshace sus instituciones básicas de atención a determinados casos: Si se crea una agencia especializada en violencia hacia los animales, rápidamente se llenará de casos; si es de maltrato al menor, al anciano, etcétera, la expectativa es que su servicio sea demandado. Por otro lado, se crea este tipo de agencias como marketing político, donde se satisface determinada necesidad social en vista de llamar la atención y arraigarse en el poder. En ocasiones, es inútil la dependencia, como en el caso de falta de personal, recursos, etcétera; por ello los programas emergen y se eliminan siempre según la voluntad y capricho político.

4. Otro aspecto está ligado al anterior: el orden político, por ejemplo, hace tiempo era delito la difamación; con el tiempo, este se deroga. Sea cualquiera el motivo que llevó al legislador a eliminarlo, implica una disminución en el tipo de delito. Ofender ya no es una conducta grave que requiera atención penal, sino que pasa a otros órdenes, ya sea civil, social, familiar, educativo, etcétera. En consecuencia, como se ha visto, la conducta desviada penal logra ese rango según la administración pública, los intereses políticos, caprichos y demás.

5. Como se mencionó en el segundo punto, la policía tiene la incapacidad de atender los asuntos que esta no considere, ya sea porque no tiene ganas, sus superiores no se lo permiten, el tipo de delito o criminal que van a perseguir está protegido, u otras razones que dejan en desprotección a la ciudadanía. Por el contrario, es cotidiana la actividad durante los retenes por alcoholímetro en las carreteras federales, aeropuertos, donde sí tienen el tiempo y paciencia para hostigar a las personas que van de paso.

\section{CLASIFICACIÓN DE LOS DELINCUENTES SEGÚN BECKER}

Becker desarrolló una tipología de delincuentes que puede ser explicada desde la teoría del etiquetamiento; a saber:

1. El desviado puro

2. El desviado acusado falsamente

3. El desviado secreto

Explica Schmalleger (2006) con ejemplos a los casos:

The pure deviant is one who commits normbreaking behavior and whose behavior is accurately appraised as such by society. An example might be the burglar who is caught in the act of burglary and then tried and convicted. Such a person, we might say, has gotten what he or she deserves. 
The falsely accused individual is one who, in fact, is not guilty but is labeled "deviant" nonetheless. The falsely accused category in Becker's typology demonstrates the power of social definition. Innocent people sometimes end up in prison, and one can imagine that the impact of conviction and of the experiences that attend prison life can leave the falsely accused with a negative self-concept and with group associations practically indistinguishable from those of the true deviant. In effect, the life of the falsely accused is changed just as thoroughly as is the life of the pure deviant by the process of labeling. Finally, the secret deviant violates social norms, but his or her behavior is not noticed, and negative societal reactions do not follow. The secret deviant again demonstrates the power of societal reaction-in this case, by the lack of consequences (p. 256).

\section{CONTROL SOCIAL Y DESVIACIÓN}

Durante el intento por controlar determinadas conductas, este proceso lleva a la creación de nuevas y más. Tal situación estimula la creatividad de los criminales; por ejemplo, el tráfico de animales y plantas exóticas. En nuestro contexto, no estamos familiarizados con determinados animales que en otras regiones son animales de carga, transporte con el que se convive, como nosotros con algunos otros. La extravagancia de ciertas personas lleva a querer poseer animales cuya posesión está prohibida en nuestras normas.

Con lo anterior, una actividad que pudiera ser considerada como cotidiana, al ser catalogada como desviada, genera desviados y nuevas modalidades para pasar desapercibido. Finalmente, no se es identificado como desviado hasta que alguien más descubra la conducta y la juzgue, alguien conferido con autoridad para tal por la sociedad. Así, se tiene que ciertos animales y plantas son traficados escondiéndoles en pelotas, bolsas, cajas, botes, entre otros objetos no propiamente portadores de estos, y que además los dañan.

En otro caso, si haber consumido alcohol o algún tipo de droga cuya percepción es fácil de destacar por el aroma, habla, ojos, entre otros aspectos, se innovan formas de disimular tales efectos, dado que son socialmente considerados como riesgosos. En cambio, en un contexto en el que la población sobresaliente está en las mismas condiciones, si se está en una cantina, bar, billar, table dance, entre otros, lo normal (no desviado) es estar embriagado, con júbilo, exaltado.

No obstante, incluso en ese mismo ambiente, existen subreglas mediante las que se permite el estado anterior, pero pasa a ser inaceptable o conflictivo cuando alguien lesiona, insulta, ofende, toca, acosa, o molesta a otro.

De tales situaciones, se toma lo que Becker señala cuando la pretensión de controlar o evitar la conducta desviada la estimula más; a saber:

1. Puede significar simplemente que, pese a que en nuestra sociedad se cometa gran cantidad de infracciones a las normas, ellas no constituyen realmente conductas desviadas, o no se las considera tales mientras ningún grupo social las rotule como pertenecientes a esa categoría.

2. Puede referirse a la posibilidad de que un actor se convierta en desviado por haber experimentado la reacción social ante una primera infracción de las normas. En síntesis, la reacción de las agencias de control social ante un primer acto desviado tiene tan poderosas repercusiones para la persona, que el individuo comienza a considerarse desviado y practica cada vez más esa conducta.

3. Puede significar que la existencia cotidiana de agencias de control social produce determinadas tasas de desviación. En ese sentido, es evidente que los índices reales de delito o desviación se obtienen gracias al funcionamiento cotidiano de la policía, los tribunales, los trabajadores sociales, etc., y que probablemente no reflejan los niveles efectivos de desviación, sino que son simplemente indicadores de la desviación de la que se ocupan las propias agencias de control social (Reyes Calderón, 2007, p. 231).

\section{CONCLUSIONES}

El poder de etiquetar conductas resulta relevante en una sociedad donde la desigualdad es imperante, situaciones que empujan a los ciudadanos a buscar otras vías de acceso a los medios para acercarse a las necesidades 
básicas. En este proceso, están involucrados diversos actores sociales como los legisladores, policías, sociedad, víctimas, delincuentes, entre otros, cada uno con sus ideales a seguir e imponer, y con justificantes para actuar. Etiquetar depende de criterios institucionales, estadísticos, morales, conceptuales, espaciotemporales y de percepción. Lo esencial en la teoría de Becker es tal proceso de constituir una conducta como desviada y las formas en que la sociedad reacciona mediante sus instituciones formales e informales. Este acto de clasificar conductas mancha, estigma y señala a las personas; las victimiza doblemente, por un lado, ser ya una minoría desproporcionada de oportunidades e igualdad, y por otro, ser castigado por serlo.

\section{REFERENCIAS BIBLIOGRÁFICAS}

Hopkins Burke, R. (2009). An introduction to Criminological theory (3a ed.). EUA: Willan Publishing.

Howies Home Page (2016). My Books. Recuperado de http://howardsbecker.com/ books.html

Lamnek, S. (2006). Teorías de la criminalidad (6 $6^{\mathrm{a}}$ ed.). México: Siglo xxi Editores.
Larrauri, E. (2009). La herencia de la criminología crítica. México: Siglo XXI Editores.

Pérez Pinzón, Á. y Pérez Castro, B. (2006). Curso de Criminología ( $7^{\mathrm{a}}$ ed.). Colombia: Universidad Externado de Colombia, pp. 95.

Quirós, C. (1995). Criminología ( $2^{\mathrm{a}}$ ed.). México: José M. Cajica.

Reyes Calderón, J. A. (2007). Tratado de Criminología ( $4^{\mathrm{a}}$ ed.). México: Cárdenas Velasco Editores, pp. 227-229.

Schmalleger, F. (2006). Criminology today. An integrative introduction ( $4^{\mathrm{a}} \mathrm{ed}$.). EUA: Pearson Prentice Hall, pp. 254-256.

Siglo XXI Editores (2016). Autores: Howard Becker Recuperado de http:// www.sigloxxieditores.com.ar/fichaAutor. php?idAutor $=1199$

Winslow, R. W. y Zhang, S. X. (2008), Criminology. A global perspective. EUA: Pearson Prentice Hall. 